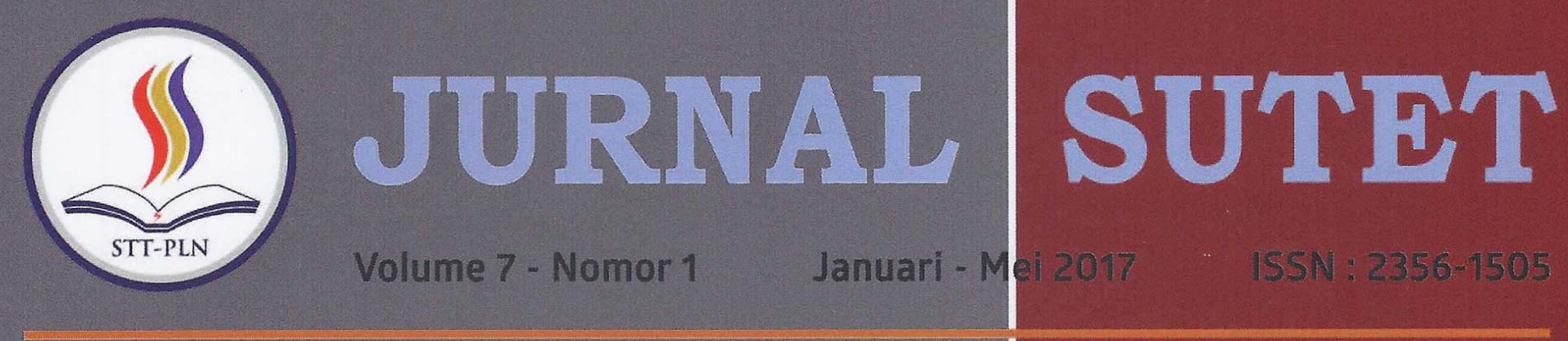

DESAIN SISTEM ALARM MOBIL BERBASIS SMS

Erlina; Hendrianto Husada; Bambang Tri Atmodjo

KELAYAKAN PENGGUNAAN PENDINGIN THERMOELEKTRIK UNTUK PENGHEMATAN DAYA LISTRIK PADA BASE TRANSCEIVER

Sunaryo; Uno Bintang Sudibyo; Supriadi Legino

WITRICITY (WIRELESS ELECTRICITY)

Aas Wasri Hasanah; Oktaria Handayani

CONCEPTUAL DESIGN FOR MITIGATING HARMONIC DISTORTION ON ESP INSTALLATION: CASE STUDY IN KAJI SEMOGA FIELD, MEDCO E\&P INDONESIA

Sandy Suryakusuma; Suprapto Atmowiranto; Dadang Darmawan

RANCANGAN RANGKAIAN ANTI BOUNCING UNTUK RANGKAIAN DIGITAL

Tasdik Darmana

STUDI POWER WHEELING DIKAWASAN INDUSTRI JABABEKA

Bimo Brillianta; Uno Bintang Sudibyo; Wildan Aripin

PEMASANGAN ARRESTER DAN ARCING HORN PADA PENGHANTAR BERISOLASI DI SUTM $20 \mathrm{kV}$ Christine Widyastuti; Andi Makkulau

PENGELOLAAN EMISI GAS LANDFILL (BIOGAS) SEBAGAI ENERGI TERBARUKAN Isworo Pujotomo; Muchamad Nur Qosim

DISAIN SISTEM PENTANAHAN PROTEKSI PETIR SISTEM MULTIPLE VERTICAL ELECTRODES PADA TERMINAL LAWE-LAWE - PERTAMINA DHP

Ibnu Hajar

ANALISA DCS (DISTRIBUTED CONTROL SYSTEM) PADA PROSES POLIMERISASI

Syarif Hidayat; Irsyadi Akbar Jay

PENGEMBANGAN TEKNOLOGI SISTEM SMART MICROGRID DI SEKOLAH TINGGI TEKNIK PLN Heri Suyanto; Agung Hariyanto

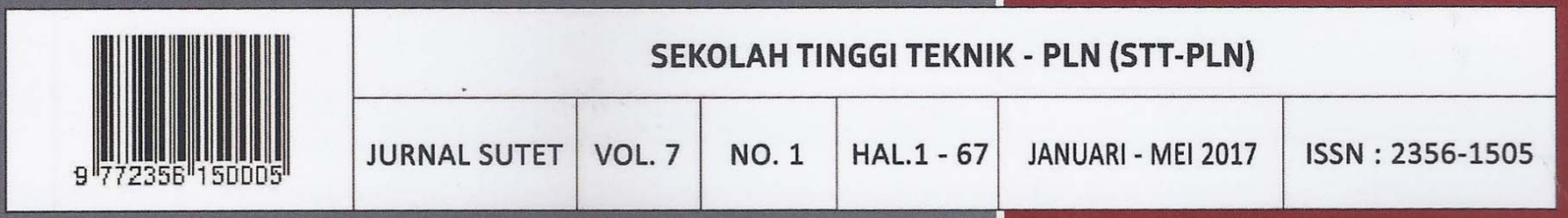




\title{
STUDI POWER WHEELING DIKAWASAN INDUSTRI JABABEKA
}

\author{
Bimo Brillianta ${ }^{1)}$, Uno Bintang Sudibyo ${ }^{2}$, Wildan Aripin ${ }^{3}$ \\ Teknik Elektro, Sekolah Tinggi Teknik-PLN, Jakarta \\ Email : ${ }^{1}$ bimoipi@gmail.com \\ 2uno@eng.ui.ac.id
}

\begin{abstract}
Electricity Jababeka industrialarea is provided by PT Bekasi Power through 150 kV PLN's own transmission with Power Wheeling concept that is the joint utilization of transmission system which has a few definitions, for example, the utilization of transmission or distribution system to transmit electric power from existing entities and to different entities. Or sending electrical power from the seller to the buyer through a system claimed by third party. In the concept of wheeling, the fees charged for services provide and bear the lossesdue to the utilization of ipower transmission networks in this study will examine the concept of appropriate power wheeling for Applied in Jababeka industrial area
\end{abstract}

Keyword : Power wheeling, transmission, industrial area

Abstrak : Kawasan industri Jababeka dipasok energi listriknya oleh pembangkit sendiri yaitu PT Bekasi Power dengan melalui transmisi 150 kV milik PLN dengan konsep Power Wheeling yaitu pemanfaatan bersama jaringan transmisi yang memiliki beberapa definisi antara lain penggunaan jaringan transmisi atau distribusi untuk mengirimkan daya listrik dari entitas yang ada dan ke entitas lain atau pengiriman daya listrik dari penjual ke pembeli melalui jaringan yang dimiliki oleh pihak ketiga Dalam konsep wheeling, biaya dibebankan untuk pelayanan yang diberikan serta menanggung rugi-rugi yang terjadi akibat adanya penggunaan jaringan transmisi tenaga listrik dalam studi ini akan mengkaji konsep power wheeling yang sesuai untuk diterapkan di kawasan industri Jababeka.

Kata Kunci : Power wheeling,transmisi,kawasan industri

\section{Pendahuluan}

Keinginan pelaku industri untuk mendapatkan jaminan keandalan pasokan dan kwalitas daya yang premium serta memiliki kemampuan untuk dapat membelinya.

Adanya kapasitas yang tidak maksimal pada jaringan transmisi serta keterbatasan investasi baik pembangkit maupun transmisi oleh PLN. Dan tidak seimbangnya antara pertumbuhan pembangkit dengan pertumbuhan jaringan Transmisi dan Distribusi di Indonesia. Tujuan penulisan ini mengkaji sistem pemanfaatan jaringan bersama pada saluran transmisi $150 \mathrm{kV}$ dan mengetahui prinsip sewa jaringan transmisi untuk pemanfaatan bersama antara pihak pemilik jaringan transmisi dengan pihak penyewa jaringan transmisi.
Sebagai bartasan masalah pada penelitian ini adalah Sistem transmisi yang menjadi objek penelitian merupakan system transmisi $150 \mathrm{kV}$ hanya di kawasan industri Jababeka. Penelitian ini difokuskan pada implementasi tiap metode penentuan biaya jaringan transmisi dengan mempertimbangkan aspek kelayakannya pada saluran transmisi $150 \mathrm{kV}$.

\section{Kajian Power Wheeling}

Kajian ini dilaksanakan dalam rangka membandingkan beberapa metode penentuan biaya jaringan transmisi yang dapat diaplikasikan dalam konsep power wheeling. Power wheeling merupakan pemanfaatan bersama jaringan tenaga listrik oleh pihak penyedia listrik lain. Pada penelitian ini PLN berperan sebagai 
institusi penyedia jasa transmisi dan pelanggan penyewa jaringan transmisi 150 kV di kawasan Jababeka oleh Bekasi Power yang merupakan perusahaan pembangkit listrik swasta. Pada bagian kajian ini akan dibahas metode yang digunakan dalam melakukan kajian pemanfaatan bersama jaringan transmisi ini.

\section{Panjang saluran}

Panjang saluran trasnmisi antara Pembangkit Bekasi Power dan kawasan Industri Jababeka adalah 5,6 km dengan tegangan $150 \mathrm{Kv}$

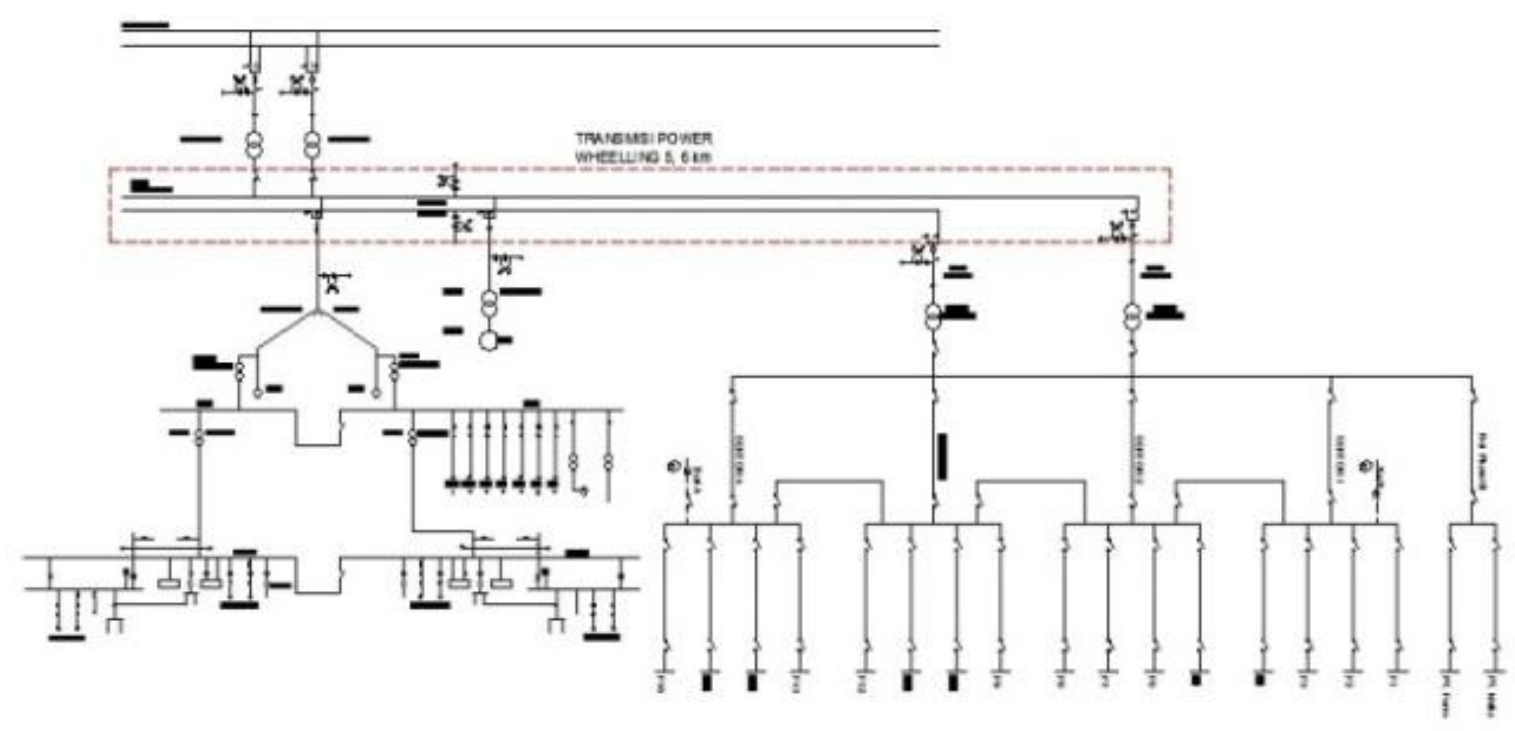

Gambar 1. Saluran Transmisi Bekasi Power ke Jababeka

\section{Jenis Penghantar}

Saluran transmisi milik PLN merupakan saluran sistem Jawa Barat sub sistem Cibatu. Tiap saluran tiap fasenya tersusun dari 2 sub penghantar. Saluran transmisi menggunakan jenis penghantar ACSR, yaitu ACSR $240 \mathrm{~mm} 2$ sirkuit ganda.

Tabel 1 Kapasitas jenis penghantar saluran transmisi $150 \mathrm{kV}$ PLN

\begin{tabular}{|c|c|c|c|}
\hline Nama & $\begin{array}{c}\text { Rated } \\
\text { Current }\end{array}$ & Voltage & $\begin{array}{c}\text { Kapasitas } \\
\text { Daya }\end{array}$ \\
\hline & (amperes) & (kilovolts) & (MVA) \\
\hline $\begin{array}{c}\text { ACSR } \\
240\end{array}$ & $2 \times 570$ & 150 & 296 \\
$\mathrm{~mm} 2$ & & & \\
\hline
\end{tabular}

\section{Metode Penelitian}

Penelitian ini berkaitan dengan metode penentuan biaya jaringan transmisi yang ingin diterapkan pada jaringan transmisi $150 \mathrm{kV}$ dari pembangkit Bekasi Power ke kawasan Jababeka. Metode-metode tersebut merupakan metode-metode yang jarang dipergunakan untuk diteliti sehingga diperlukan adanya sistematika proses yang saling mendukung dan terkait, sehingga dapat mencapai tujuan penelitian yang telah ditentukan. Dengan adanya sistematika tersebut, diharapkan setiap proses akan mempengaruhi proses kajiaan secara keseluruhan. Pada bagian ini akan dijelaskan tentang tahapan kajian tentang metode penentuan biaya jaringan transmisi untuk jaringan transmisi $150 \mathrm{kV}$ dari pembangkit Bekasi Power ke kawasan Jababeka.

\subsection{Diagram Alir Penelitian}




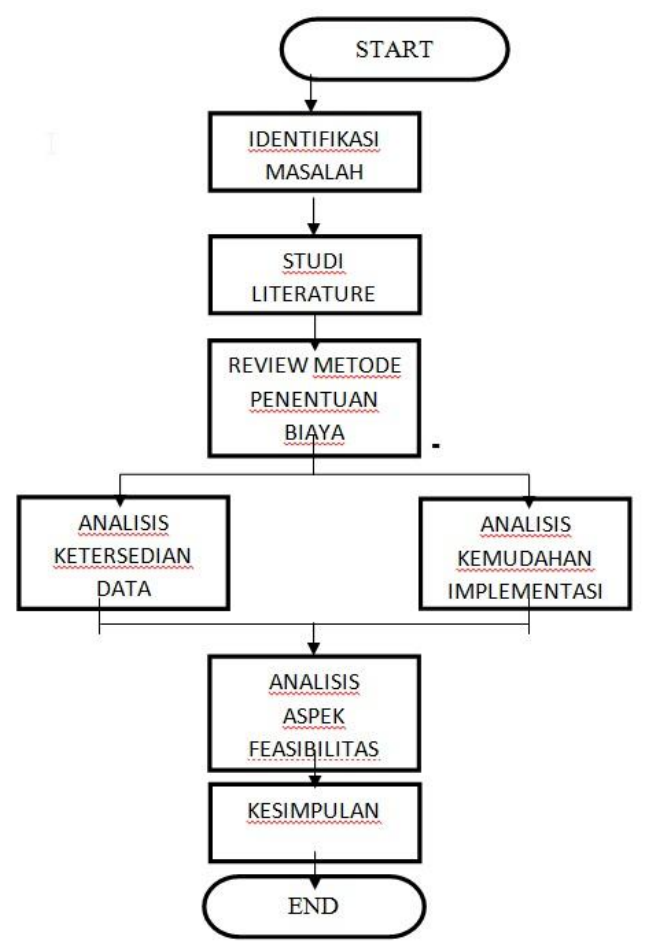

\section{ANALISA DAN PEMBAHASAN}

Kajian tentang metode penentuan biaya jaringan transmisi merupakan faktor penting untuk menentukan metode yang tepat dalam penentuan biaya saluran transmisi. Dalam menentukan biaya jaringan transmisi yang adil dan tanpa diskriminatif, pemanfaatan saluran transmisi harus ditentukan dengan tepat untuk dapat mengimplementasikan penentuan biaya transmisi berbasis penggunaan jaringan.

\subsection{Kajian Penentuan Biaya}

Dalam menentukan biaya jaringan transmisi yang adil dan tanpa diskriminatif, pemanfaatan saluran transmisi harus ditentukan dengan tepat untuk dapat mengimplementasikan penentuan biaya transmisi berbasis penggunaan jaringan. Namun, menentukan pemanfaatan saluran transmisi yang akurat merupakan hal yang tidak mudah, dikarenakan sifat aliran daya yang tidak linier. Selain itu, biaya tersebut harus dapat mencakup keseluruhan biaya jaringan. Biaya keseluruhan transmisi tersebut terdiri dari biaya operasi, perawatan, administrasi, investasi serta biaya kapital jaringan. Kajian ini dilaksanakan dalam rangka membandingkan beberapa metode penentuan biaya jaringan transmisi untuk diaplikasikan dalam power wheeling.

Metode-metode perhitungan biaya transmisi, sebagai dasar implementasi konsep power wheeling,. Beberapa metode penentuan biaya jaringan transmisi akan dibahas pada tulisan, antara lain:

1) Metode Postage Stamp,

2) Metode Contract Path,

3) Metode MW-Mile,

4) Metode MVA-Mile

\subsubsection{Metode Postage Stamp}

Metode Postage Stamp merupakan metode penentuan biaya jaringan transmisi yang saat ini digunakan dalam sistem kelistrikan di Indonesia. Biaya jaringan transmisi dibebankan berdasarkan total biaya keseluruhan jaringan transmisi dibagi dengan jumlah energi listrik yang dibangkitkan dikurangi susut jaringan. Kemudian biaya tersebut menjadi biaya rata-rata pengguna jaringan transmisi. Sehingga biaya yang dibebankan kepada pengguna jaringan transmisi menggunakan metode postage stamp merupakan tarif flat, dimana semua pelanggan jaringan transmisi dibebankan dengan tarif yang sama. Oleh karena itu, terjadi diskriminasi terhadap pengguna jaringan transmisi dengan penggunan jaringan yang rendah.

$$
W C_{t}=T C \times \frac{P_{t}}{P_{\text {peak }}}
$$

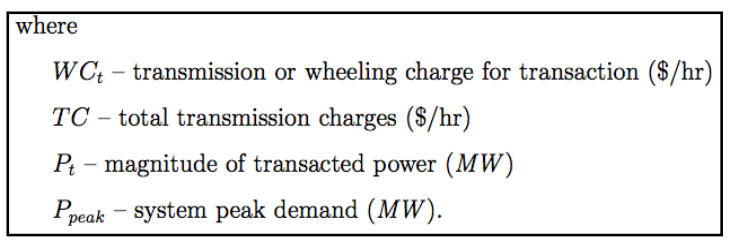

\subsubsection{Metode Contract Path}

Metode contract path merupakan metode yang didasarkan kepada asumsi bahwa pelayanan jaringan transmisi pada keseluruhan sistem dapat direpresentasikan dengan aliran daya transmisi yang mengalir pada jalur transmisi fiktif tertentu (contract path). Kemudian biaya jaringan transmisi dapat ditentukan menggunakan metode postage stamp.

Metode ini tidak memerlukan adanya perhitungan aliran daya. Besar biaya yang 
telah ditentukan dengan metode ini menjadi biaya seluruh pengguna jaringan transmisi. Sehingga biaya yang dibebankan kepada pengguna jaringan transmisi menggunakan metode contract path juga merupakan tarif flat atau datar.

$$
\begin{aligned}
& W C_{t}=T C_{k} \cdot \frac{P_{t}}{P_{k}} \\
& \text { where } \\
& T C_{k}: \text { Transmission cost in path } \\
& P_{k}: \text { Transmission line capacity in path } \\
& \text { In equation (2) } \mathrm{TC}_{k} \text { is the transmission cost in path and } \mathrm{P}_{k} \\
& \text { is the transmission line capacity in path. }
\end{aligned}
$$

\subsubsection{Metode MW-Mile}

Metode MW-Mile merupakan metode yang memperhitungkan biaya jaringan transmisi berdasarkan besar aliran daya transmisi dalam MW dan panjang saluran transmisi dalam mil. Dalam beberapa aplikasi, panjang saluran transmisi juga dapat dinyatakan dalam satuan kilometer. Metode ini merupakan metode penentuan biaya jaringan transmisi pertama yang memperhitungkan biaya aktual penggunaan jaringan transmisi berbasis perhitungan power flow arus searah (DC).

Metode ini memperhitungkan biaya setiap transaksi tenaga listrik yang berhubungan dengan penggunaan kapasitas transmisi, besar daya transaksi, jalur yang digunakan dan jarak saluran transmisi yang dilalui.

$$
T C_{t}=T C \times \frac{\sum_{k \in K} c_{k} L_{k} M W_{t, k}}{\sum_{t e T} \sum_{k e K} c_{k} L_{k} M W_{t, k}}
$$

Where, $\mathrm{TC}_{\mathrm{t}}=$ cost allocated to transaction $\mathrm{T}(\$ / \mathrm{Hr})$

$\mathrm{MW}_{\mathrm{t}, \mathrm{k}}=$ flow in facility $\mathrm{k}$ due to transaction $\mathrm{t}$ in $\mathrm{MW}$

$\mathrm{C}_{\mathrm{k}}=$ cost per MW per unit length of line $\mathrm{k}$

$\mathrm{L}_{\mathrm{k}}=$ length of line $\mathrm{k}$ in mile

$\mathrm{TC}=$ total cost of all lines in $\$$

$\mathrm{T}, \mathrm{K}=$ set of transactions and lines respectively

\subsubsection{Metode MVA-Mile}

Pada prinsipnya perhitungannya sama dengan MW-mile method, namun telah mempertimbangkan baik real power dan reactive power. Metode sebelumya tidak memperhitungakan reactive power

$$
T C_{t}=T C \times \frac{\sum_{k \subset K} c_{k} L_{k} M V A_{t, k}}{\sum_{t e T} \sum_{k e K} c_{k} L_{k} M V A_{t_{k} k}}
$$

Where, $\mathrm{MVA}_{\mathrm{t}, \mathrm{k}}=$ flow in facility $\mathrm{k}$ due to transaction $\mathrm{t}$ in MVA

\section{Kesimpulan dan saran}

\section{Kesimpulan}

Dari pembahasan pada bab-bab sebelumnya mengenai metode penentuan biaya jaringan transmisi untuk penentuan tarif wheeling data jaringan transmisi 150 kV antara Bekasi Power ke PLN dan ke Kawasan industri Jababeka terdapat beberapa hal yang dapat dibandingkan diantara metode-metode penentuan biaya jaringan transmisi. Setiap metode penentuan biaya jaringan transmisi memiliki kelebihan dan kekurangan masing-masing dalam aplikasi wheeling tenaga listrik

1. Postage Stamp :sederhana, mencakup keseluruhan biaya jaringan transmisi namunidak merefleksikan penggunaan jaringan yang sebenarnya.

2. Contract Path : sederhana, mencakup keseluruhan biaya jaringan transmisi, bila dibandingkan dengan metode postage stamp, metode ini tidak merefleksikan penggunaan jaringan yang sebenarnya dan memungkinkan adanya investasi di luar jalur kontrak yang telah ditentukan.

3. MW-Mile: membutuhkan analisis power flow dc, menggambarkan penggunaan jaringan yang sebenarnya namun tidak mempertimbangkan kapasitas jaringan yang tidak digunakan (unused capacity), sehingga belum tentu mencakup keseluruhan biaya.

4. MVA-Mile: membutuhkan analisis power flow ac, menggambarkan penggunaan jaringan yang sebenarnya, mempertimbangkan aliran daya reaktif, sehingga memberikan sinyal biaya jaringan yang lebih baik dibandingkan metode MW-Mile namun tidak mempertimbangkan kapasitas jaringan yang tidak digunakan (unused capacity), sehingga belum tentu mencakup keseluruhan biaya.

Dari ketersediaan data yang dimiliki oleh PT Bekasi Power saat ini, metode yang paling siap untuk diaplikasikan 
sebagai biaya jaringan transmisi dalam aplikasi wheeling tenaga listrik pada sistem jaringan transmisi di Jababeka adalah kombinasi metode contract path, MVA - Mile dan Postage Stamp

\section{Saran}

1. Perlu dilakukan studi yang terkait dengan kapasitas jaringan transmisi 500 kV, 150 kV Jawa-Bali, untuk mengetahui resiko pada saluransaluran yang dapat terjadi dalam aplikasi power wheeling tenaga listrik.

2. Perlu dilakukan studi yang terkait perhitungan model tarif tiap metode penentuan biaya jaringan dan perbandingannya terhadap ancialiary service dan imbalance service jaringan transmisi, untuk mengetahui perbandingan tiap metode penentuan biaya jaringan secara kwalitatif dan kuatitatif.

\section{Referensi}

Allen J Wood, Bruce F.Wollenberg (1996), Power Generation Operation and Control Second Edition John Wiley \& Sons, Inc New York ,Toronto, Singapore

Bialek, J. (1996). Tracing The Flow of Electricity. in IEE Proceeding Generation Transmission Distribution. Vol. 143 No. 4, July.

Bialek, J. (1997). Topological Generation and Load Distribution and Load Distribution Factor for Supplement Charge Allocation in Transmission Open Access. in IEEE Transactions on Power Systems. Vol. 12 No. 3 page 1185-1193, August 1997.

Caramanis, M, C., R, E, Bokn., dan F, C, Schweppe., (1986). The Costs of Wheeling and Optimal Wheeling Rates. in IEEE Transactions on Power Systems. Vol. 1 No. 1 page 63-73, February.

Cyrinus Egeruoh Chigoziri (2012) Thesis Long Term Transmission Expansion Planning For Nigerian Deregulated Power System $A$ systems approach Delft University of Technology.
Hamada, H., H, Tanaka., dan R, Yokoyama., (2009). Wheeling Charge Based on Identifications of Transaction Paths in Deregulated Power Markets. Universities Power Engineering Conference (UPEC), Proceedings of the 44th International. page 1-5.

Peraturan Menteri Energi Sumber Daya Mineral No 01/ 2015 Tentang Kerjasama Penyediaan Tenaga Listrik dan Pemanfaatan Bersama Jaringan Tenaga Listrik Kementerian ESDM.

JICA Survey Team, Power Wheeling, Seminar Masyarakat Kelistrikan Indonesia Jakarta December 2015

Kharbas, B., M, Fozdar., dan H, Tiwari., (2011). Transmission Tariff Allocation Using Combined MW-Mile \& Postage Stamp Methods. in IEEE PES Innovative Smart Grid Technologies India. page 6-11

Kharbas, B., M, Fozdar., dan H, Tiwari., (2013). Comparative assessment of MW-Mile and MVA-Mile methods of transmission tariff allocation and revenue reconciliation. in IEEE PES Power and Energy Society General Meeting, . page 1-5, July. 